\title{
Characterization of Two Factors Enhancing Choline Acetyltransferase Activity in Cultures of Purified Rat Motoneurons
}

\author{
Jean Claude Martinou,, Agathe Le Van Thai, ${ }^{1}$ Georges Cassar, ${ }^{2}$ Francis Roubinet, ${ }^{2,3}$ and Michel J. Weber ${ }^{1}$ \\ 'Laboratoire de Pharmacologie et de Toxicologie Fondamentales, Centre National de la Recherche Scientifique 205, \\ 31077 Toulouse Cedex, France, 'Service Commun d'Analyse et de Tri Cellulaire, Universite Paul Sabatier, Hopital Purpan, \\ Toulouse, France, and ${ }^{3}$ Centre Regional de Transfusion Sanguine de Toulouse, CHU Purpan, 31052 Toulouse Cedex, \\ France
}

\begin{abstract}
Motoneurons from E14 rat embryos have been retrogradely labeled with the carbocyanine derivative dil and purified 12fold by centrifugation on a density gradient made of Nycodenz, as assessed by the increase in CAT activity per cell and in the percentage of dil-labeled cells. A 20- to 36-fold purification was achleved by the microdissection of the labeled lumbar motor columns followed by density-gradient centrifugation. Motoneurons were then purified to near homogeneity by fluorescence-activated cell sorting. In certain experiments, motoneurons were purified by a novel cellsorting procedure that only uses light-scatter parameters and does not necessitate retrograde labeling.

In cultures of motoneurons enriched by centrifugation, muscle-conditioned media (CM) had only a marginal effect on the overall neuronal survival but increased up to 10-fold the number of labeled motoneurons surviving after $7 \mathrm{~d}$ in culture. CAT activity per culture was quantitatively stimulated to the same extent, suggesting that the increase in CAT activity caused by CM mostly reflected better survival of motoneurons. In cultures of motoneurons purified by cell sorting, CM increased both survival and CAT expression per motoneuron.

We have partially purified 2 factors from $\mathrm{CM}$ that stimulate CAT activity per motoneuron 2- to 3-fold without affecting their survival. One of these factors is probably identical to the factor involved in the cholinergic/noradrenergic choice of sympathetic neurons (Fukada, 1985).
\end{abstract}

Retrograde trophic interactions between neurons and their field of innervation play a major role in the development of the nervous system (Levi-Montalcini, 1987). In particular, it is commonly assumed that, during the period of naturally occurring cell death, the survival and differentiation of vertebrate motoneurons is controlled by factors secreted in limiting amounts by muscle tissues (Prestige, 1967, 1970; Hollyday and Hamburger, 1976; Hamburger, 1977; Chu-Wang and Oppenheim, 1978).

Received July 8, 1988; revised Mar. 14, 1989; accepted Apr. 14, 1989.

We thank Dr. A. C. Kato and Dr. J. Peschon for helpful comments. This work was supported by funds from the Centre National de la Recherche Scientifique, the Association Francaise contre les Myopathies, and from the Institut pour la Recherche sur la Moelle Epiniere.

Correspondence should be addressed to J. C. Martinou, Department of Pharmacology, Box 8103, Washington University School of Medicine, 660 South Euclid Avenue, St. Louis, MO 63110.

Copyright @ 1989 Society for Neuroscience $0270-6474 / 89 / 103645-12 \$ 02.00 / 0$
The characterization of factors capable of stimulating the development of motoneurons in culture is the subject of intense research. Muscle extracts or conditioned media (CM) have been shown to enhance the survival of cultured motoneurons (Bennett et al., 1980; Smith et al., 1985; Dohrmann et al., 1986; Gurney et al., 1986; O'Brien and Fischbach, 1986), to stimulate neurite outgrowth (Dribin and Barrett, 1980, 1982; Henderson et al., 1981, 1983; Calof and Reichardt, 1984, 1985), and to increase CAT activity in spinal cord cultures (Giller et al., 1977; Giess and Weber, 1984; Kaufman et al., 1985; Smith et al., 1985; McManaman et al., 1988).

Compared with similar studies performed on PNS cultures, the determination of the mode of action of these factors is made difficult by the cellular heterogeneity of embryonic spinal cord cultures. In particular, CAT-stimulating factors have usually been characterized using high-density cultures, so that it is unclear whether motoneurons, rather than interneurons or nonneuronal cells, are the target of these factors. Furthermore, it was generally not established whether stimulation of CAT development resulted from a better survival of motoneurons and/ or from an increase in CAT activity per motoneuron. In some cases, the increases in CAT per culture caused by CM did not exceed those of total protein or neurofilament protein and could thus be attributed to a general effect on neuronal survival rather than to a specific effect on motoneurons (Kaufman et al., 1985; Doherty et al., 1986). By staining cholinergic neurons in spinal cord cultures with anti-CAT antibodies, Smith et al. (1986) characterized a high- $M_{r}$ factor that stimulates ACh synthesis but does not affect the number of CAT-positive cells, whereas low$M_{r}$ factors increased both parameters.

In a previous study (Giess and Weber, 1984), we found that a factor stimulating CAT and AChE activities in high-density cultures of rat embryonic spinal cord copurified with a factor involved in the noradrenergic/cholinergic choice of sympathetic neurons. We made the hypothesis that these 2 factors were identical. Although it has been shown conclusively that this factor stimulates CAT activity in sympathetic neurons without affecting their survival (Patterson and Chun, 1977; Swerts et al., 1983), it remained to be determined if the same was true for motoneurons.

In this study, motoneurons from E14 rat embryos have been retrogradely labeled with a carbocyanine dye, purified by density-gradient centrifugation and cell sorting, and cultured on monolayers of cortex astrocytes. We show that muscle CM contains factor(s) that selectively affect the survival of motoneurons and 2 factors that stimulate CAT expression without affecting 
Figure 1. Determination of the lightscatter parameters of motoneurons. The hindlimbs of E14 rat embryos were injected with diI. After retrograde transport, cells dissociated from the spinal cords were fractionated on a Nycodenz gradient. Ten thousand cells from fraction A were analyzed with the cell sorter. The data are displayed as 3 planar cytograms, where the intensity of the spots is proportional to the number of events. Cytogram B (fluorescence intensity vs axial scatter) allows one to determine the axial scatter parameters of brightly fluorescent cells from peak III (horizontal arrowheads). Cytogram $\mathrm{C}$ (fluorescence intensity vs orthogonal scatter) similarly determines the window of orthogonal scatter associated with brightly fluorescent cells (vertical arrowheads). These values define the quadrangle in cytogram $A$ used for blind sorting.
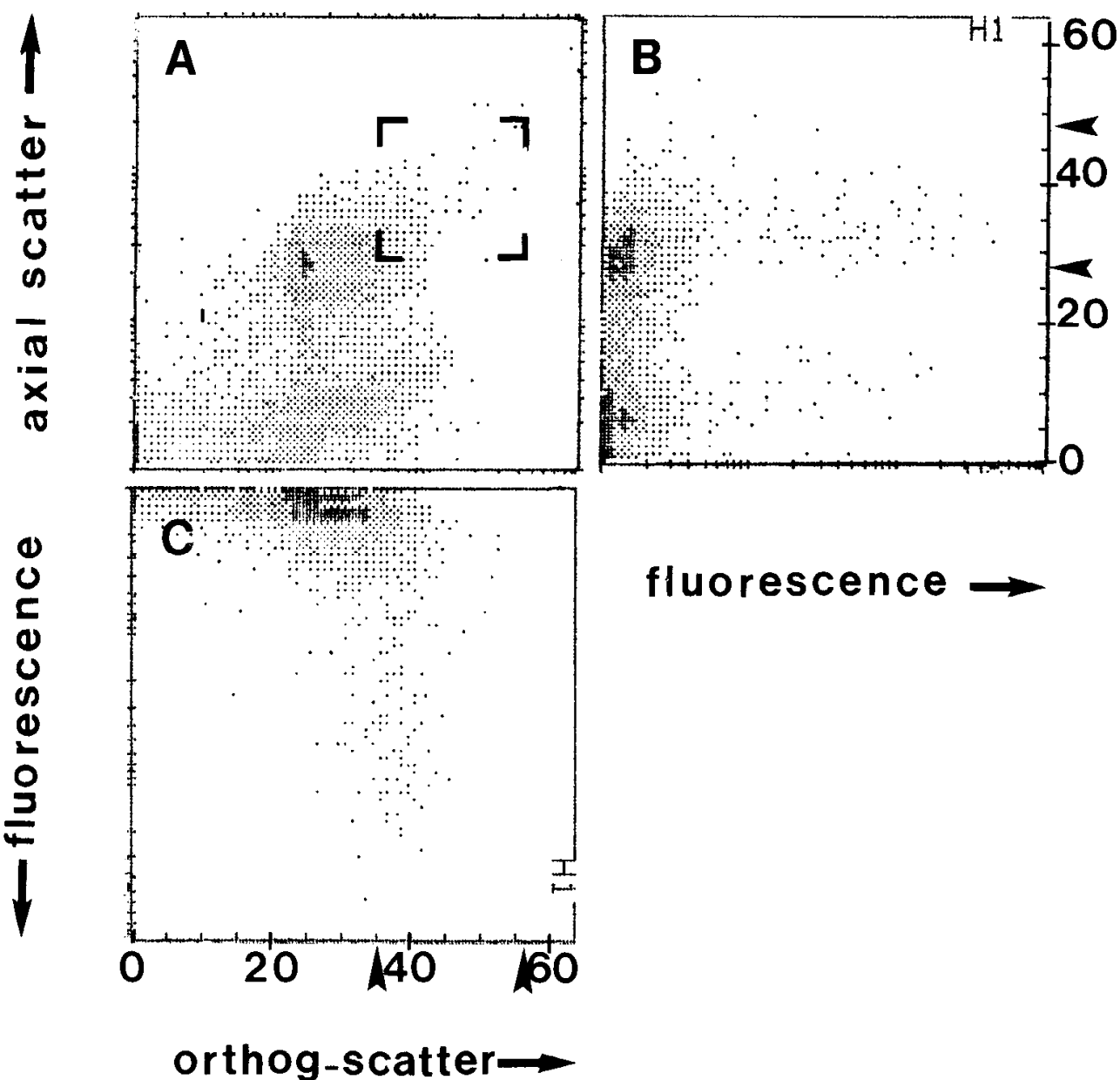

\section{fluorescence $\rightarrow$}
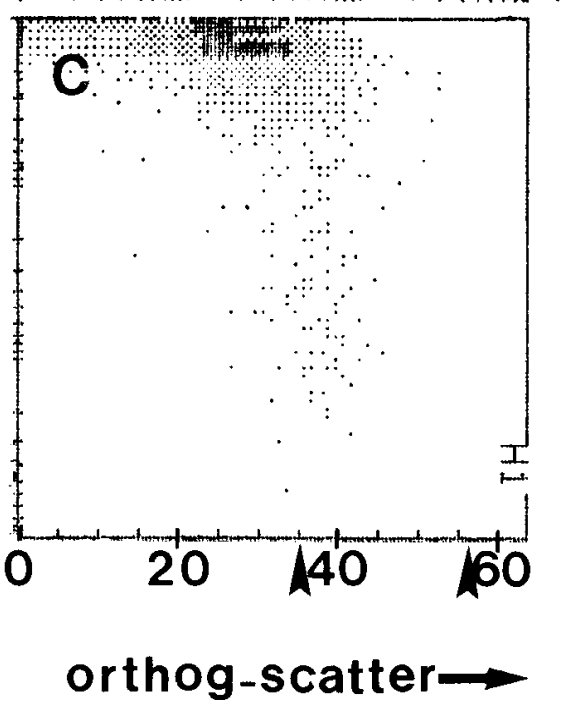

survival. One of the CAT-stimulating factors copurifies in 4 steps with the cholinergic factor for sympathetic neurons.

\section{Materials and Methods}

Retrograde labeling of embryonic motoneurons. The retrograde labeling was performed as described by Landmesser (1978) using 1,1'-dioctadecyl-3-3,3'3'-tetramethylindocarbocyanine perchlorate or diI (Molecular Probes, Eugene, OR), a dye that persists in labeled cells for many days and is not transferred to adjacent cells (Honig and Hume, 1986). E14 rat embryos were decapitated and eviscerated in Leibowitz's L15 medium supplemented with glucose and antibiotics. Two $\mu$ l of a 2 $\mathrm{mg} / \mathrm{ml}$ dil solution in ethanol were injected at multiple points in the hindlimbs. After a dorsal laminectomy, the embryos were pinned on Sylgard in a Petri dish containing the culture medium described by Calof and Reichardt (1984). The dish was placed on a rocking table so that the embryos were half of the time either immersed in medium or exposed to a $95 \% \mathrm{O}_{2}, 5 \% \mathrm{CO}_{2}$ atmosphere. Retrograde labeling was performed for $20-24 \mathrm{hr}$ at $31^{\circ} \mathrm{C}$ in the presence of $0.05 \%$ soybean trypsin inhibitor (Schaffner et al., 1987).

Density-gradient centrifugation of motoneurons. The spinal cord from labeled embryos was dissected free of meninges and dorsal root ganglia. When needed, the lumbar motor column was microdissected under an inverted fluorescence microscope. The tissue was incubated for $20 \mathrm{~min}$ at $37^{\circ} \mathrm{C}$ in $0.05 \%$ trypsin, washed with $\mathrm{Ca}, \mathrm{Mg}$-free Hank's saline solution (CMF), and dissociated by trituration.

A $2 \mathrm{ml}$ cell suspension obtained from 2 entire spinal cords or 20 lumbar motor columns was layered on a discontinuous density gradient made with Nycodenz (Nycgaard and Co., Oslo, Norway) and composed of two $3 \mathrm{ml}$ layers of density 1.047 and $1.065 \mathrm{gm} / \mathrm{ml}$. (For unknown reasons, an upper layer of density 1.043, rather than 1.047, gave better results when using uninjected E1 4 embryos.) After centrifugation for 20 min at $2500 \times g$ in a Beckman JS 7.5 rotor at $4^{\circ} \mathrm{C}$, fractions were collected with a Pasteur pipette and centrifuged for $15 \mathrm{~min}$ at $100 \times g$ on a $5 \mathrm{ml}$ cushion of $4 \%$ BSA in CMF to remove cellular debris and soluble enzymes (Calof and Reichardt, 1984; Dohrmann et al., 1986). The final pellet was resuspended in CMF at $1-2 \times 10^{6} \mathrm{cell} / \mathrm{s} / \mathrm{ml}$.

Purification of motoneurons by fluorescence-activated cell sorting. A Coulter Epics $C$ cell sorter equipped with a $5 \mathrm{~W}$ argon laser and a 76 $\mu \mathrm{m}$ nozzle tip was used. Particles were analyzed for axial and orthogonal light scatters, and for fluorescence intensity at a rate of $800 / \mathrm{sec}$. The fluorescence of diI was excited at $514 \mathrm{~nm}(200 \mathrm{~mW})$ and analyzed through classical rhodamine optics. Although the threshold of autofluorescence was situated at channel 30 , channel 66 was selected as the fluorescence intensity threshold for cell sorting to eliminate unlabcled cells that had adsorbed debris of fluorescent cells during tissue dissociation. When examined with a fluorescence microscope, $90-95 \%$ of the sorted cells were brightly fluorescent. Sorled cells were collected with the Coulter Autoclone system in 96 well trays containing astrocytic monolayers (see below). About $6 \mathrm{hr}$ elapsed between the time of dissociation of the tissue and the beginning of the culture.

To determine the light-scatter parameters of dead and living cells, embryos were injected with ethanol rather than dil and incubated at $31^{\circ} \mathrm{C}$ for $20 \mathrm{hr}$ in the presence of $0.05 \%$ soybean trypsin inhibitor. After density gradient centrifugation, cells from fraction A were incubated either with $1 \mu \mathrm{g} / \mathrm{ml}$ propidium iodide (a dye taken up only by dead cells) or $0.5 \mu \mathrm{g} / \mathrm{ml}$ acridine orange (a dye taken up only by living cells) and analyzed with the cell sorter (Saint-John et al., 1986).

Purification of motoneurons without retrograde labeling. To define the light scatter parameters characteristic of motoneurons, diI-labeled motoneurons were enriched on a Nycodenz gradient and analyzed with the cell sorter. The data were used to generate 3 dual-parameter cytograms (orthogonal scatter vs axial scatter, fluorescence vs axial scatter, and fluorescence vs orthogonal scatter), which were then oriented to bring the common axes side by side (Fig. 1). The cytogram of fluorescence vs axial scatter allowed us to define the lower and upper limits of axial 
scatter produced by the brightly fluorescent cells from peak III. Similarly, the cytogram of fluorescence vs orthogonal scatter allowed us to define the window of orthogonal scatter produced by the brightly fluorescent cells. This defined a quadrangle in the cytogram of axial scatter vs orthogonal scatter where fluorescent motoneurons, but possibly also unlabeled ones, were located (this population can be clearly seen on the 3-dimensional histogram of Figure $8 A$ as a trailing edge of peak III).

To validate this analysis, diI-labeled motoneurons were sorted in the quadrangle of the cytogram of axial scatter vs orthogonal scatter at $90^{\circ}$, without using fluorescence as a criterion for sorting (blind sorting). The analysis of the sorted cells showed that the blind sorting increased the proportion of fluorescent neurons from 5 to $31 \%$. Then using the same cell suspension, cells from peak III displaying a fluorescence intensity above channel 66 were purified as described in the previous paragraph. Similar increases in CAT activity per cell were obtained with the blind sorting and with fluorescence-activated sorting (data not shown). This suggested that the blind sorting could significantly enrich motoneurons.

The blind-sorting technique was then repeated with uninjected E14 rat embryos. Obviously, this type of sorting relied on the similarity of the cytograms (axial scatter vs orthogonal scatter) obtained with uninjected and injected embryos, and, indeed, only subtle differences were observed (data not shown). Routinely, the upper limit of both axial and orthogonal scatters were set at channel 64 (see Fig. 1). The lower limit of axial scatter was set between channels 25 and 30 ; small variations in this parameter did not affect the result of the sorting. The success of the blind-sorting procedure mostly relied on the choice of the lower limit of orthogonal scatter. For example, when this limit was varied from channel 37 to 35 , the cell content of the quadrangle varied from $1-2 \%$ to $7 \%$ of the total cell population. Preliminary experiments performed with diI-labeled motoneurons showed that the optimal enrichment in fluorescent cells was obtained when the quadrangle contained $1-2 \%$ of the population. In each experiment, the lower limit of orthogonal scatter was adjusted to fulfill this condition.

Cultures of purified motoneurons. Cultures of astrocytes from newborn rat cortex were prepared by the method of McCarthy and De Vellis (1980) as described by Martinou et al. (1989). Purified motoneurons were cultured on a monolayer of living astrocytes in the culture medium described by Giess and Weber (1984). In control experiments, neuronal countings were performed before and after staining with anti-neurofilament antibodies. This showed that neurons could easily he distinguished from the flat, nonrefractile astrocytes, which, in the culture conditions used, did not display long cytoplasmic extensions. Therefore, neuronal countings were routinely performed with phase microscopy.

CAT assay. The neurons were lysed in $0.2 \mathrm{M} \mathrm{NaCl}, 0.2 \%$ Triton $\mathrm{X}-100$ and centrifuged at $12,000 \times g$ for 2 min. For the CAT assay, $10 \mu \mathrm{l}$ of the neuronal homogenate was mixed with $20 \mu$ lof assay mix as described by Fonnum (1975). To increase the sensitivity of the assay, the concentration of ${ }^{3} \mathrm{H}$-acetyl $\mathrm{CoA}(1.6 \mathrm{Ci} / \mathrm{mmol})$ was reduced to $3.2 \mu \mathrm{M}$ without isotopic dilution. The reaction was linear with cell homogenate volume and time, until $30 \%$ of the labeled substrate was exhausted (Raynaud et al., 1987). Because the concentration of ${ }^{3} \mathrm{H}$-acetyl CoA was subsaturating, CAT activity was expressed in cpm rather than pmol, ${ }^{3} \mathrm{H}$-acetylcholine (ACh) formed. After a $20 \mathrm{~min}$ incubation at $37^{\circ} \mathrm{C}$, the reaction was stopped with $10 \mu \mathrm{l}$ formiate/acetate buffer at $\mathrm{pH} 2$ containing $1 \mathrm{mg} / \mathrm{ml}$ choline and ACh. ${ }^{3} \mathrm{H}-\mathrm{ACh}$ was separated from ${ }^{3} \mathrm{H}$ acetyl $\mathrm{CoA}$ by high-voltage paper electrophoresis (Hildebrand et al., 1971 ) and counted by liquid scintillation. The background of the assay was $60-100 \mathrm{cpm}$. CAT activity in a culture containing 500 motoneurons was at least 10 -fold higher than background. A large variability in CAT activity was observed between independent sets of cultures, possibly originating from differences in the precise stage of the embryos. Therefore, only comparisons between cultures from the same experiment are relevant.

Fractionation of muscle-CM. CM from secondary or tertiary cultures of skeletal muscle cells was prepared as described by Swerts et al. (1983). The initial purification steps were performed according to Weber (1981) and Weber and Le Van Thai (1982). CM was supplemented with 2.5 mM Na $\mathrm{NG}_{2}$ ETA and $0.3 \mathrm{~mm}$ phenylmethylsulfonylfluoride. The protein precipitating between 60 and $100 \%$ saturation in ammonium sulfate at $0^{\circ} \mathrm{C}$ (P100 fraction) was dialyzed against $5 \mathrm{~mm}$ Na phosphate, $0.3 \mathrm{~mm}$ $\mathrm{Na}_{2}$ EGTA, pH 7 (buffer A), and applied sequentially to DEAE- and $\mathrm{CM}$-cellulose columns in buffer $\mathrm{A}$. The neutral fraction unretained by these 2 columns was concentrated by ammonium sulfate precipitation to give $\mathrm{CM}$-cellulose fraction 1. The $\mathrm{CM}$-cellulose column was eluted with $0.25 \mathrm{M} \mathrm{NaCl}$ in buffer $\mathrm{A}$ to give $\mathrm{CM}-$-cellulose fraction 2. This fraction was applied to a hydroxyapatite column (HA, IBF, France) equilibrated with $0.25 \mathrm{M} \mathrm{NaCl}$ in buffer $A$. The material not retained by this column, called the HA fraction, was collected. The different fractions were mixed with culture medium and filter sterilized, and were added to the cultures from day 0 onward.

\section{Results}

\section{Retrograde labeling of rat embryo motoneurons with diI}

Twenty hours after the injection of diI in the hindlimb of E14 rat embryos, the label in the spinal cord was confined to the anlage of the ipsilateral motor column (Fig. $2 A$ ) and to sensory nerve fibers in the dorsal horns (see Fig. 3). In sections of the whole embryo, a few scattered neurons were labeled in the dorsal root ganglia (not shown). In cryostat sections from a similar axial level, cholinesterase activity, as revealed with the method of Karnovski and Roots (1964), was localized to the anlage of the lateral motor column and to a lesser extent to the ventral epithelium. In certain sections, another group of cells was also labeled (Fig. $2 B$ ); these were situated in a medial position and presumably corresponded to the anlage of the visceral motor column. Although no double-labeling experiments were done, this second group of esterase-positive cells did not appear to be labeled with diI.

The labeled lumbar motor column was easily localized by observing the whole, unfixed spinal cord with fluorescence microscopy (Fig. 3). This structure was then microdissected and the dorsal horn as well as the unlabeled region near the central canal were removed. This microdissection resulted in an 8-fold enrichment in fluorescent neurons (see below). In typical experiments, bilateral injections in the hindlimbs were performed on 20 embryos, yielding 4000-6300 fluorescent neurons per embryo after dissociation.

\section{Separation of spinal cord cells on Nycodenz density gradients}

In a first series of experiments, cells dissociated from the entire spinal cord of diI-injected embryos were fractionated on density gradients made of Nycodenz. The best enrichment in CAT activity/cell was obtained with a discontinuous gradient composed of 2 layers of densities 1.047 and $1.065 \mathrm{gm} / \mathrm{ml}$. Three factors were collected: fraction $\mathrm{A}$ at the upper interface $(d<1.047)$, fraction B between $d=1.047$ and 1.065, and fraction $\mathrm{C}(d>$ 1.065), which formed a pellet. The unfractionated cell suspension (referred to as fraction NS) contained $0.18 \%$ fluorescent cells (Table 1, upper panel). In fraction A, $2.1 \%$ of the cells were fluorescent, a 12-fold increase over fraction NS. CAT activity (expressed on a per cell basis) was also increased 12-fold. Fraction A contained $2.7 \%$ of the initial cell number, $31 \%$ of the initial fluorescent cells, and $32 \%$ of the total CAT activity. This fraction was also enriched about 3-fold in AcChE activity and contained $12 \%$ large, strongly esterase-positive cells. On the contrary, less than 2-fold differences in GAD activity per cell were observed among the gradient fractions (data not shown).

We then determined whether a further enrichment in motoneurons could be achieved with the same gradient but using cells from the dissected lumbar motor columns (LMC), rather than from the whole spinal cord. In the starting cell suspension, $1.5 \%$ of the cells were fluorescent (Table 1, lower panel), suggesting that the microdissection enriched fluorescent cells 8 -fold. In fraction $\mathrm{A}$, the percentage of fluorescent cells was now $6.6 \%$, a 4-fold increase over the nonseparated LMC cell fraction. Similarly, CAT activity per cell was enriched 6.7-fold over the LMC cell fraction. This fraction now contained 30\% largc, strongly esterase-positive cells (data not shown). 


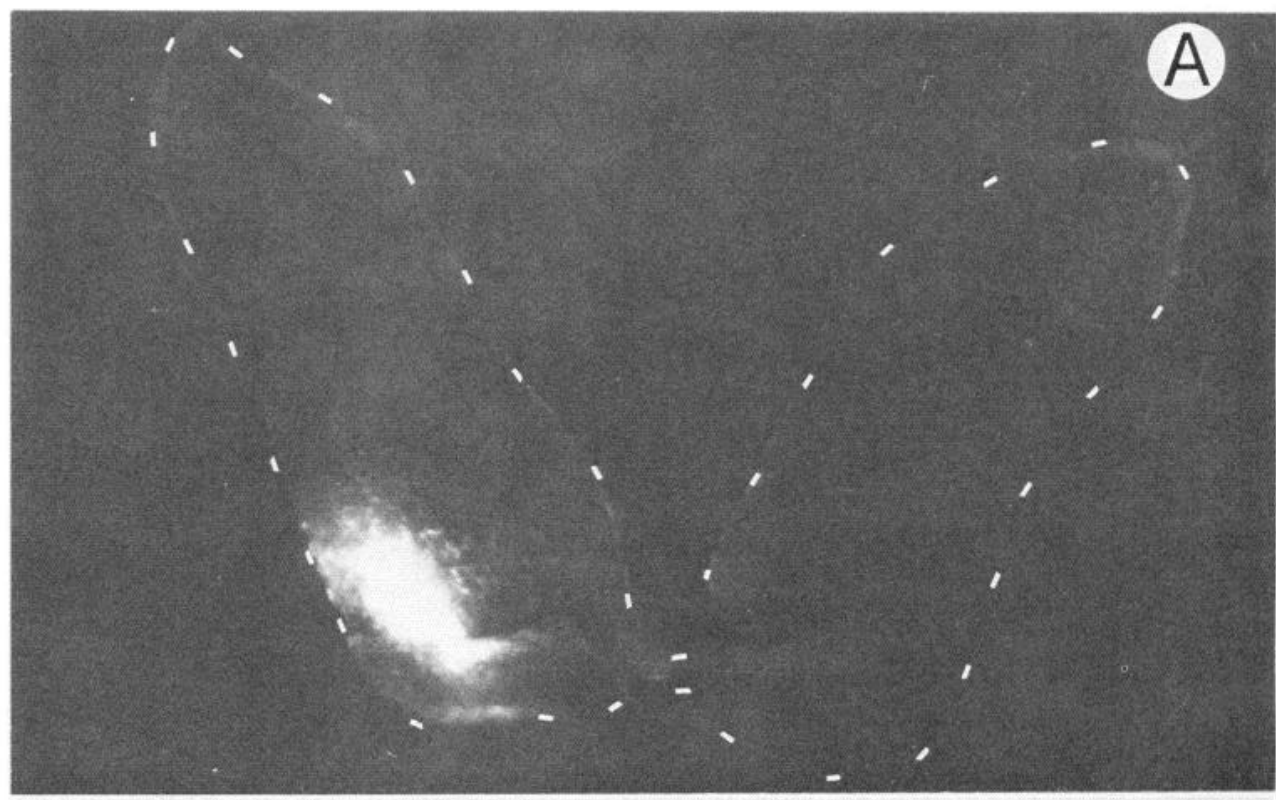

Figure 2. Localization of diI fluorescence and of esterase activity on sections of embryonic spinal cord. $A$, Fluorescence of diI. The left hindlimb of a E14 embryo was injected with diI. After $24 \mathrm{hr}$, the spinal cord was dissected, fixed with $4 \%$ formaldehyde, impregnated in sucrose, and sectioned (16 $\mu \mathrm{m})$ with a cryostat. $B$, Visualization of esterase activity by the method of Karnovski and Roots (1964).

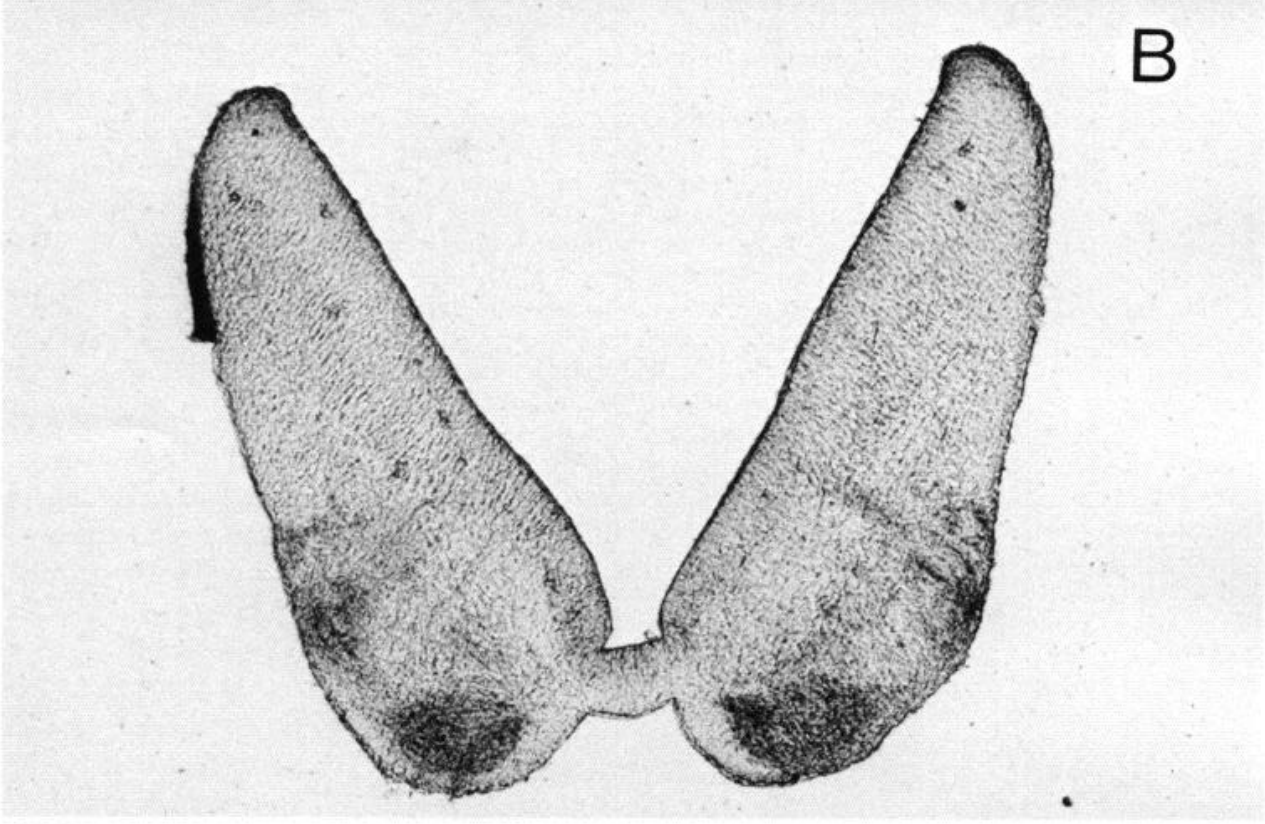

In most experiments performed either with entire spinal cords or with LMC, a significant increase in the proportion of fluorescent cells in fraction C was observed, whereas this fraction was relatively depleted in CAT activity. These cells were distinctly smaller than those present in fraction A (data not shown); they may be immature motoneurons expressing a low level of CAT activity. Moreover, it was observed that CAT activity per fluorescent neuron was maximal in fraction $\mathrm{B}$, which suggests that this fraction is enriched in cholinergic cells other than motoneurons.

\section{Development of CAT activity in cultures from density-gradient fractions}

Cells dissociated from entire spinal cords were separated on a Nycodenz gradient. Fractions NS, A, B, and C were cultured for $10 \mathrm{~d}$ at low density $\left(2 \times 10^{4} / \mathrm{cm}^{2}\right)$ on a monolayer of newborn rat cortex astrocytes either in the absence $\left(\mathrm{CM}^{-}\right.$medium) or presence $\left(\mathrm{CM}^{+}\right.$medium) of $50 \%$ muscle-CM. As shown on Figure $4 A$, the development of CAT activity per neuron was maximal in cultures from fraction $A$ under both culture conditions. CM stimulated CAT development in the 4 culture types, but, again, this effect was maximal in cultures from fraction A. In $\mathrm{CM}^{+}$medium, CAT activity was 10 -fold higher in cultures A than in cultures NS, a figure similar to the 12-fold enrichment in CAT activity per cell obtained in fraction A after the densitygradient centrifugation. Figure $4 B$ shows the kinetics of CAT activity per neuron in cultures from fraction $\mathrm{A}$ : whereas CAT activity failed to develop in $\mathrm{CM}^{-}$medium, a steady increase up to day 10 was observed in $\mathrm{CM}^{+}$medium. The development of AcChE activity was also maximal in cultures from fraction A and was stimulated 2- to 3-fold by CM (data not shown). 

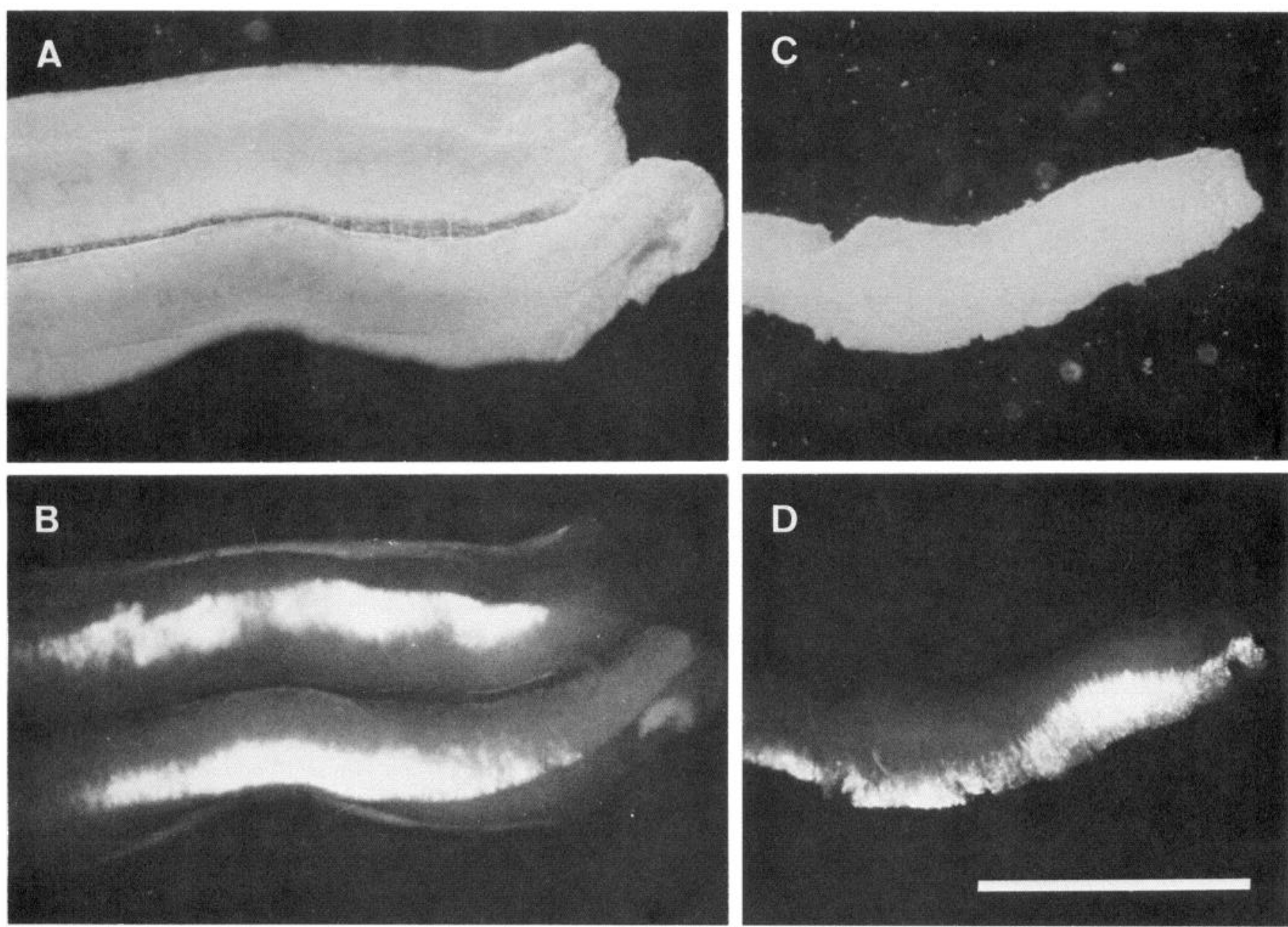

Figure 3. Localization and dissection of the lumbar motor column after retrograde labeling. After a bilateral injection of diI in the hindlimbs, the spinal cord was dissected free of meninges and sensory ganglia. The unfixed spinal cord was examined with a phase contrast ( $A$, $C$ ) or a rhodamine fluorescence optics $(B, D)$. $A$ and $B$, Ventral views of the lower third of the spinal cord. Note the bright fluorescence of the motor columns and the faint labeling of sensory nerve fibers in the dorsal horns. $C$ and $D$, The region of the right motor column has been microdissected by 2 transversal cuts and by removing the dorsal horns and the region near the central canal. Scale bar, $1 \mathrm{~mm}$.

\section{Beneficial effect of $C M$ on the survival of retrogradely labeled motoneurons}

The main objective of this study was to assess if the stimulation of CAT development by CM was attributable to a beneficial effect on the survival of motoneurons or on their differentiation (i.e., to an increase in CAT activity per motoneuron). To address this question, cultures from fraction $\mathrm{A}$ were maintained either in $\mathrm{CM}^{-}$or $\mathrm{CM}^{+}$medium. The total number of neurons was counted by phase microscopy, and labeled motoneurons by fluorescence microscopy. As shown in Figure 5, motoneurons labeled with diI rapidly extended neurites when cultured on astrocytes. A long, axon-like process developed, and even the filopodia of growth cones were distinctly fluorescent.

In both $\mathrm{CM}^{-}$and $\mathrm{CM}^{+}$media, the total number of neurons decreased by half between days 1 and 5 (Fig. 6A). CM had no effect on overall neuronal survival up to day 8 , although a slight beneficial effect was sometimes observed in older cultures (data not shown). In contrast, $\mathrm{CM}$ had strong beneficial effects on the survival of fluorescent neurons (Fig. 6B). First, CM increased the initial attachment of fluorescent neurons to the astrocytic monolayer, as $62 \%$ of their initial number were scored as living after $1 \mathrm{~d}$ in $\mathrm{CM}^{+}$medium, as compared with $41 \%$ in $\mathrm{CM}^{-}$ medium. Second, CM decreased the rate of decay of fluorescent neurons; the number of fluorescent neurons decreased by $90 \%$ between day 1 and 8 in $\mathrm{CM}^{-}$medium as compared with $40 \%$ in $\mathrm{CM}^{+}$medium. The percentage of fluorescent neurons steadily decreased from 6 to $2 \%$ between days 2 and 8 in $\mathrm{CM}^{-}$medium, whereas it increased to $12 \%$ in $\mathrm{CM}^{+}$medium. At day $8, \mathrm{CM}^{+}$ cultures contained about 10 -fold more fluorescent neurons than $\mathrm{CM}^{-}$cultures.

CAT activity at day 8 was 12 -fold higher in $\mathrm{CM}^{+}$cultures when expressed per dish or per neuron (Fig. $6 \mathrm{C}$ ). On the other hand, CAT activity per fluorescent neuron was unaffected (Fig. $6 D$ ). Because of the low number of fluorescent neurons in $\mathrm{CM}^{-}$ cultures, this calculation had a large error margin. However, in 3 similar experiments, the ratio of CAT activities per dish in $\mathrm{CM}^{+}$over $\mathrm{CM}^{-}$medium was $7.6 \pm 2.8$ (mean $\pm \mathrm{SEM}$ ), whereas the ratio of CAT activities per fluorescent neuron was $0.98 \pm$ 0.16 . Consequently, the stimulation of CAT activity per culture caused by CM could be quantitatively accounted for by its beneficial effect on the survival of fluorescent neurons. 

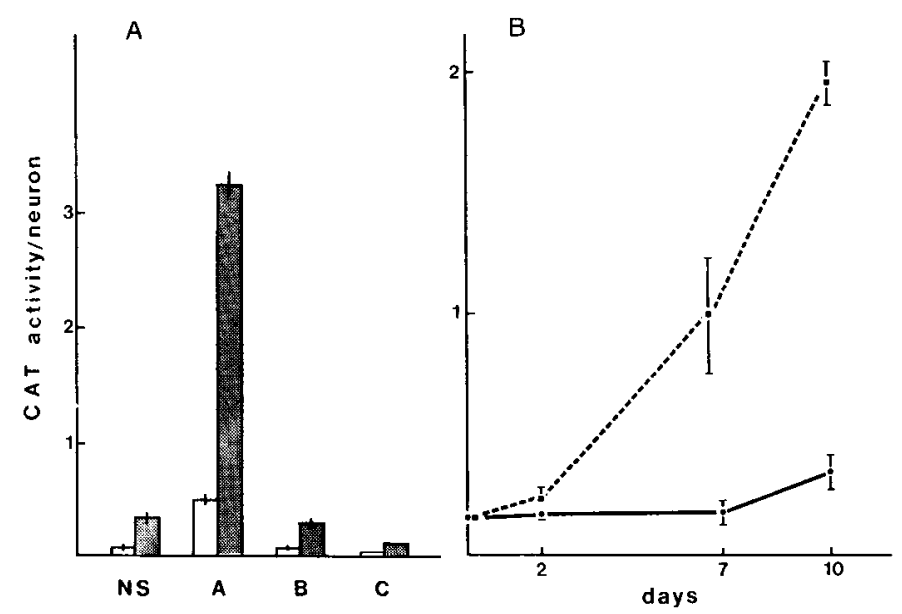

Figure 4. CAT activity in cultures prepared from the fractions of a discontinuous density gradient. $A$, Cells of the unfractionated spinal cord $(N S)$ and of fractions A-C from a density gradient were cultured for $10 \mathrm{~d}$ on monolayers of cortex astrocytes, at an initial density of 4 $\times 10^{4}$ spinal cord cells $/ 16 \mathrm{~mm}$ well. The cultures were maintained in the absence (open bars) or presence (hatched bars) of 50\% C.M. In this and in subsequent figures, CAT activity is expressed in $\mathrm{cpm}{ }^{3} \mathrm{H}-\mathrm{ACh}$ formed in $20 \mathrm{~min}$. The data are means \pm SEM for 3 sister cultures. The effects of CM are significant at the $p<0.01$ (fraction C) or $p<0.001$ level (other fractions). $B$, Kinetics of CAT development in cultures from fraction A maintained in the presence $(--)$ or absence $(-)$ of $50 \%$ $\mathrm{CM}$. The effects of $\mathrm{CM}$ at day 10 are significant at the $p<0.001$ level. The data are means \pm SEM for 3 cultures. $A$ and $B$ are from 2 independent experiments.

\section{Characterization of 2 cholinergic differentiation factors from muscle-CM}

The CM was fractionated using procedures described by Weber (1981) and Fukada (1985) to purify a factor that induces CAT expression in rat sympathetic neurons. $\mathrm{CM}$-cellulose fraction 1 , unretained by both DEAE- and CM-cellulose columns in 5 mM phosphate buffer, $\mathrm{pH} 7$, does not stimulate CAT expression in these cultures, whereas $\mathrm{CM}$-cellulose fraction 2 , which is eluted from the $\mathrm{CM}-$ cellulose column by $250 \mathrm{mM} \mathrm{NaCl}$, induces
CAT up to 200-fold (Weber, 1981; Fukada, 1985). These fractions, as well as CM, were tested on cultures enriched in diIlabeled motoneurons (Table 2). In agreement with the data from Figure 6, CM produced similar increases in the survival of fluorescent neurons and in CAT activity per culture and had no significant effect on CAT activity per fluorescent neuron. However, it was surprising to find that both $\mathrm{CM}$-cellulose fractions 1 and 2 increased CAT activity per culture 2.6- to 3.2 -fold without increasing the survival of fluorescent neurons. Consequently, CAT activity per fluorescent neuron was increased up to 2.4-fold. Obviously, such a calculation was the subject of a large error margin due to the low number of fluorescent cells in certain cultures. Nevertheless, the experiment of Table 2 suggested that $\mathrm{CM}$ contained a factor or factors that affected specifically the survival of motoneurons and at least two other factors stimulating CAT expression without affecting motoneuron survival. It is important to note that in the experiment of Table 2 , the protein $(25 \mu \mathrm{g})$ added to $1 \mathrm{ml}$ of culture medium was extracted from 14 and $54 \mathrm{ml}$ of muscle-CM for fractions 1 and 2 , respectively. It is thus plausible that these 2 factors were originally present in $\mathrm{CM}$ at concentrations too low to exert significant effects on CAT expression.

$\mathrm{CM}-$ cellulose fraction 2 was further purified on an hydroxyapatite column to give fraction HA (see Materials and Methods). This fraction $(20 \mu \mathrm{g} / \mathrm{ml})$ stimulated CAT development in rat sympathetic ncuron cultures 80 -fold (data not shown). Doseresponse curves for CAT stimulation by $\mathrm{CM}$-cellulose fractions 1 and HA in cultures enriched in motoneurons are presented in Figure 7. CAT activity increased linearly with the amount of CM-cellulose fraction 1, a 4-fold stimulation being observed with $80 \mu \mathrm{g} / \mathrm{ml}$. A 2.5-fold stimulation was obtained with $60 \mu \mathrm{g} /$ $\mathrm{ml}$ of fraction $\mathrm{HA}$, the highest concentration tested. These data suggested that fraction HA contained a factor stimulating CAT activity in both sympathetic neurons and motoneurons, possibly identical to that purified by Fukada (1985). On the other hand, $\mathrm{CM}$-cellulose fraction 1 contains a factor with a different targetcell specificity. To better characterize this new factor, we studied its effects on cultures of motoneurons purified to near homogeneity by cell sorting.

Table 1. Fractionation of rat spinal cord cells on Nycodenz density gradients

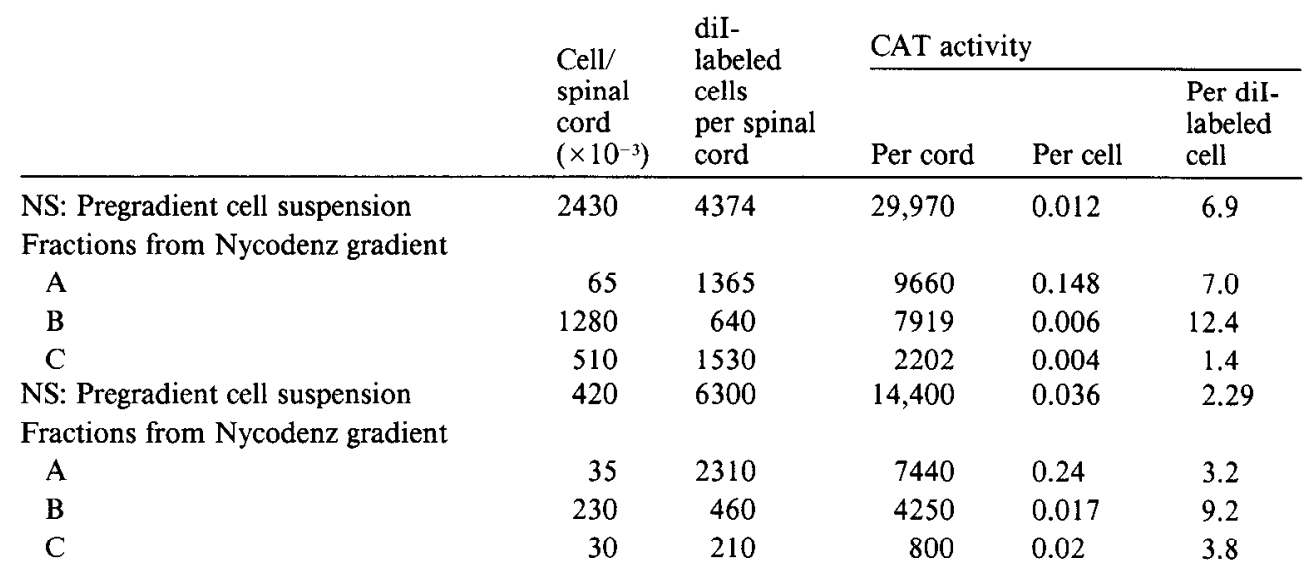

Cells dissociated from the spinal cord of E14 embryos (upper half) or from the dissected lumbar motor columns (lower half) were separated on Nycodenz density gradients. Cell fractions were analyzed for their content in diI-labeled cells and for CAT activity (expressed in $\mathrm{cpm}{ }^{3} \mathrm{H}$-ACh formed in $20 \mathrm{~min}$ ). The data are representative of 9 (upper half) or 5 (lower half) experiments. 

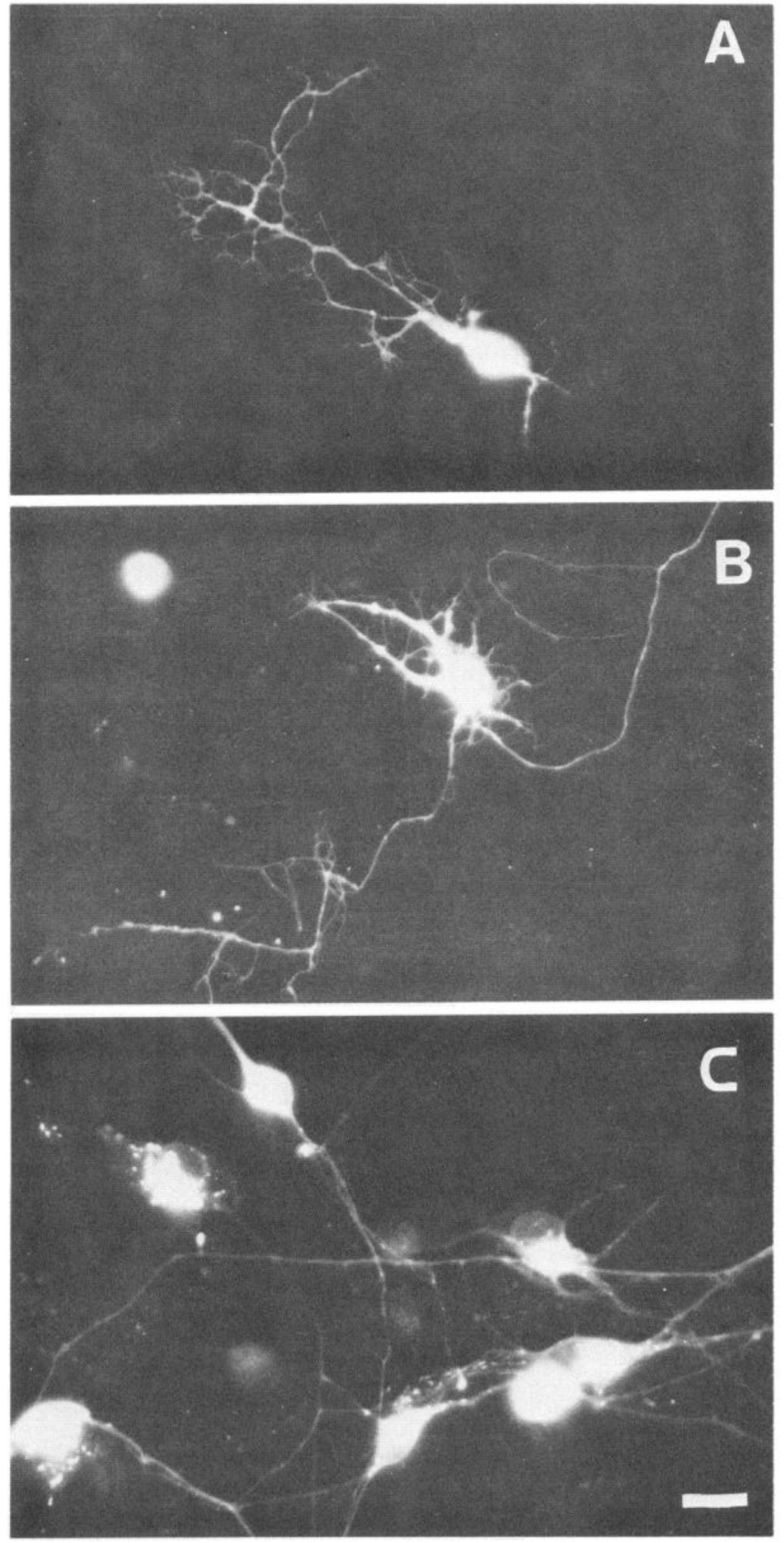

Figure 5. Fluorescence micrographs of retrogradely labeled motoneurons in culture. $A$ and $B$, Motoneurons from E14 rat embryos were retrogradely labeled with diI, enriched on a Nycodenz gradient and cultured for $6 \mathrm{~d}$ on a monolayer of cortex astrocytes. Note in $B$ a brightly fluorescent cell that failed to attach to astrocytes. $C$, diI-labeled motoneurons were purified by cell sorting and cultured for $7 \mathrm{~d}$ on astrocytes. Scale bar (on $C$ ), $25 \mu \mathrm{m}$.

\section{Cell sorting of motoneurons labeled with diI}

After the retrograde labeling with diI, the dissection of the LMC and the density-gradient centrifugation, cells from fraction A were analyzed with a cell sorter. Each particle was characterized by its fluorescence intensity, by light scattering at low angles (referred to as axial scatter), and by light scattering perpendicular to that of the incident beam (orthogonal scatter). The results of an analysis are displayed as 3-dimensional histograms in Figure 8 . When the number of events was plotted versus the axial scatter and the orthogonal scatter (Fig. $8 \mathrm{~A}$ ), the population was subdivided into 3 main peaks. Peak I produced very little light scattering and displayed little or no fluorescence above the autofluorescence threshold. This peak contained mainly cellular 
Figure 6. Effects of $\mathrm{CM}$ on the survival and differentiation of retrogradely labeled motoneurons in culture. Motoneurons were retrogradely labeled with diI, and cells from the entire spinal cords were fractionated on a density gradient. Cells from fraction A were cultured for $8 \mathrm{~d}$ on a monolayer of astrocytes. $A$, Overall survival of neurons, in the presence (-- ) or absence ( - ) of $50 \%$ CM. B. Survival of the motoneurons counted with the fluorescence optics. C, CAT activity in the same cultures was measured at day 8 . Hatched bars, cultures maintained in the presence of CM; clear bars, cultures in the absence of CM. D. CAT activities are expressed per fluorescent neuron. The tures. In $B$, the effect of CM is significant at the $p<0.001$ level (day 1) or the $p<0.005$ level (days 5 and 8 ); in $C$, the effect is significant at the $p<$ 0.001 level. counted with the phase-contrast optic, data are means \pm SEM for 3 sister cul-
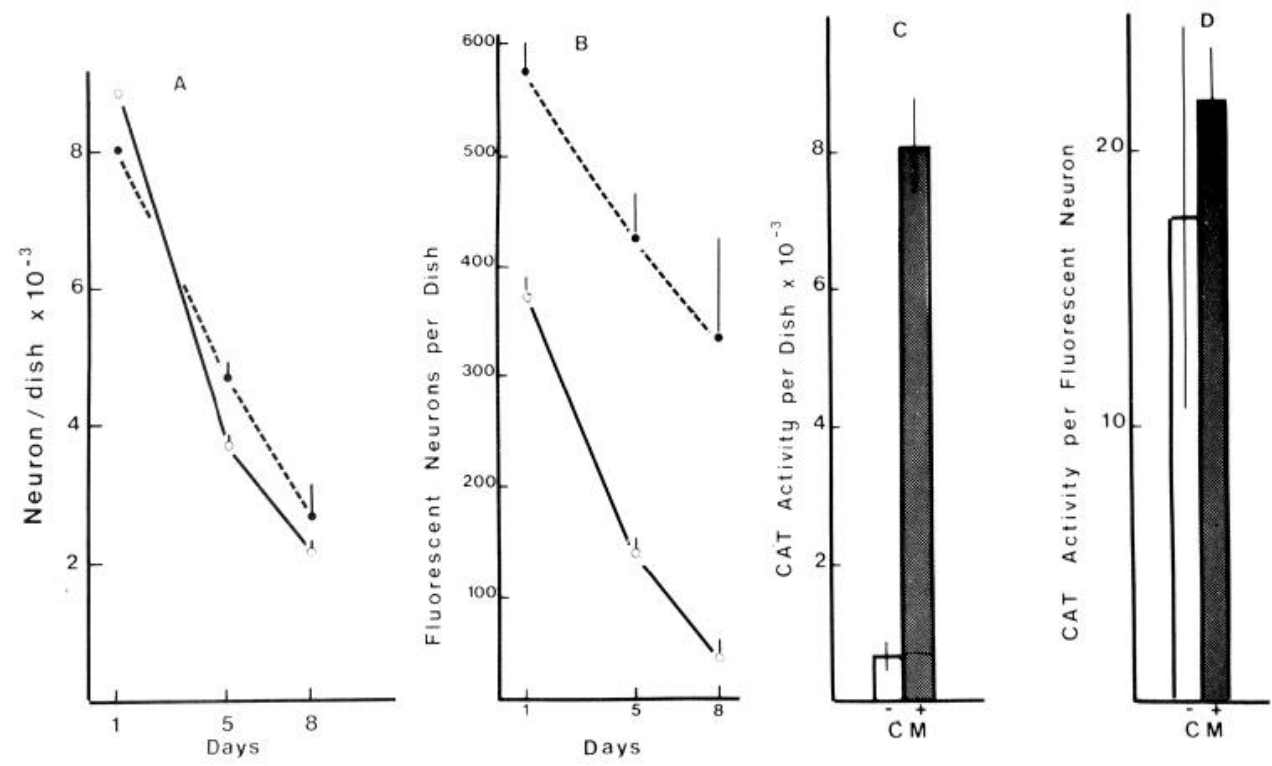

debris and could be greatly reduced by centrifuging the cell suspension over a BSA cushion before cell sorting (see Materials and Methods). Peaks II and III were clearly separated by their axial scatter and displayed overlapping, but not identical, orthogonal scatter. Both of them contained highly fluorescent cells (Fig. $8 B$ ). In experiments performed with embryos not injected with diI, $96-98 \%$ of cells from peak III took up acridine orange and excluded propidium iodide and were thus living. By the same criteria, peak II contained $30-46 \%$ dead cells (data not shown, see Materials and Methods). Consequently, we sorted out cells from peak III which displayed a fluorescent intensity above channel 66 . When examined with a fluorescence microscope, at least $90 \%$ of the purified neurons were brightly fluorescent (data not shown). The cell sorting resulted in a 9- to 10 -fold increase in CAT activity per cell over fraction A.

\section{Survival and differentiation of purified motoneurons}

DiI-labeled motoneurons purified with the cell sorter were collected directly into culture wells $\left(0.6-1.3 \times 10^{4}\right.$ motoneurons/ $16 \mathrm{~mm}$ dish) containing a monolayer of astrocytes from newborn rat cortex and cultured in $\mathrm{CM}^{+}$or $\mathrm{CM}^{-}$medium. About $50 \%$ of the cells adhered to the substratum and rapidly extended fine neurites (Fig. $5 C$ ). In the absence of $\mathrm{CM}, 10.2 \pm 4.5 \%$ (mean \pm SEM, 6 independent experiments with 2-3 cultures each) of the neurons initially plated survived after $7 \mathrm{~d}$ as compared with $15.4 \pm 5.0 \%$ in the presence of $\mathrm{CM}$. In these 6 experiments, the ratio of surviving neurons in $\mathrm{CM}^{+}$over $\mathrm{CM}^{-}$medium was 1.8 \pm 0.2 (range, 1.2-2.4); the beneficial effects of $\mathrm{CM}$ on motoneuron survival was significant in $4 / 6$ experiments. In the same experiments, CAT activity per dish was increased $3.72 \pm 0.74$ fold (range, 1.5-6), a significant effect in 5 of 6 experiments. CAT activity per motoneuron was increased $2.24 \pm 0.54$-fold (range, 1.3-4.8) (Fig. 9). Consequently, CM had beneficial effects on both the survival of purified embryonic motoneurons and on the expression of CAT. These 2 effects contributed about equally to the stimulation of CAT development per culture.

Under similar conditions, CM-cellulose fraction $1(25 \mu \mathrm{g}$ protein $/ \mathrm{ml}$ ) caused a nonsignificant $(15 \%)$ decrease in the survival of motoneurons; however, CAT activity per motoneuron was increased 3-fold (Fig. 9).

\section{Effects of CM on motoneurons purified without retrograde labeling}

During the course of this study, we developed a method (referred to as blind sorting) to purify motoneurons to $>50 \%$ purity without retrograde labeling, using only axial and orthogonal light

Table 2. Effect of $\mathrm{CM}$ and fractions from CM-cellulose on the CAT activity of low-density motoneuron cultures

\begin{tabular}{|c|c|c|c|c|}
\hline & Neuron/dish & $\begin{array}{l}\text { Fluorescent } \\
\text { neurons/dish }\end{array}$ & $\begin{array}{l}\text { CAT } \\
\text { activity/dish }\end{array}$ & $\begin{array}{l}\text { CAT } \\
\text { activity/ } \\
\text { fluorescent } \\
\text { neuron }\end{array}$ \\
\hline Control & $2208 \pm 98$ & $60 / 30 / 30$ & $681 \pm 112$ & $18 \pm 5$ \\
\hline $50 \% \mathrm{CM}$ & $2746 \pm 307$ & $420 / 330 / 240$ & $8099 \pm 646$ & $22 \pm 1$ \\
\hline $\mathrm{CM}$-cellulose fraction $1(25 \mu \mathrm{g} / \mathrm{ml})$ & $2165 \pm 165$ & $0 / 60 / 0$ & $2198 \pm 261$ & 36 \\
\hline CM-cellulose fraction $2(25 \mu \mathrm{g} / \mathrm{ml})$ & $2416 \pm 175$ & $30 / 90 / 30$ & $1757 \pm 125$ & $44 \pm 11$ \\
\hline
\end{tabular}

Motoneurons were retrogradely labeled with diI, enriched on a Nycodenz density gradient and cultured for $7 \mathrm{~d}$ at low density $\left(2 \times 10^{4} / \mathrm{cm}^{2}\right)$ on a monolayer of astrocytes. Sister cultures were maintained in fresh medium, in $50 \%$ CM or in medium supplemented with CM-cellulose fraction 1 or 2 . Neuron counts and CAT measurements were performed on day 7 . 
scatter parameters as sorting criteria (see Materials and Methods). This has the advantage of the rapid yield of a larger, alth.ough less pure, population of motoneurons. In some experiments, the survival of these neurons in culture was distinctly better than those obtained by cell sorting.

Table 3 shows that muscle-CM increased both the survival of these neurons and CAT activity per neuron. On the other hand, CM-cellulose fraction 1 had no effect on neuronal survival but increased CAT activity per neuron 1.6 -fold. Therefore, this fraction, as well as CM, had similar effects on motoneurons purified by conventional cell sorting or by the blind sorting procedure.

\section{Discussion}

It is well established that muscle-CM or muscle extracts stimulate the development of CAT activity in cultures prepared from rat embryonic spinal cord (Giller et al., 1977; Giess and Weber, 1984; Kaufman et al., 1985; Smith et al., 1985). The objective of this study was to distinguish among factors released by cultured skeletal muscle cells, those that specifically had a beneficial effect on motoneuron survival from those that could stimulate $\mathrm{CA} \Gamma$ activity per motoneuron without affecting their survival. To do that, we used low-density cultures in which motoneurons could be easily identified. This was achieved by the retrograde labeling of motoneurons with diI and their purification by density-gradient centrifugation and cell sorting.

\section{Retrograde labeling of motoneurons}

DiI was chosen for retrograde labeling because it persists in cells for many days and is not transferred to adjacent cells (Honig and Hume, 1986). Labeled motoneurons were unambiguously identified in 10-d-old cultures. On the contrary, rhodamine isothiocyanate or dye-conjugated lectins used in previous studies (McPheeters and Okun, 1980; Calof and Reichardt, 1984; Dohrmann et al., 1986; Smith et al., 1986; O'Brien and Fischbach, 1987; Schaffner et al., 1987) are eliminated from motoneurons after 3-4 d in vitro.

Although the proportion of motoneurons in rodent embryonic spinal cord is smaller than in chick embryos (Hamburger, 1975; Oppenheim et al., 1978; Lance-Jones, 1982), the percentage of labeled cells in rat embryonic spinal cord after retrograde labeling reported by different laboratories varies considerably.

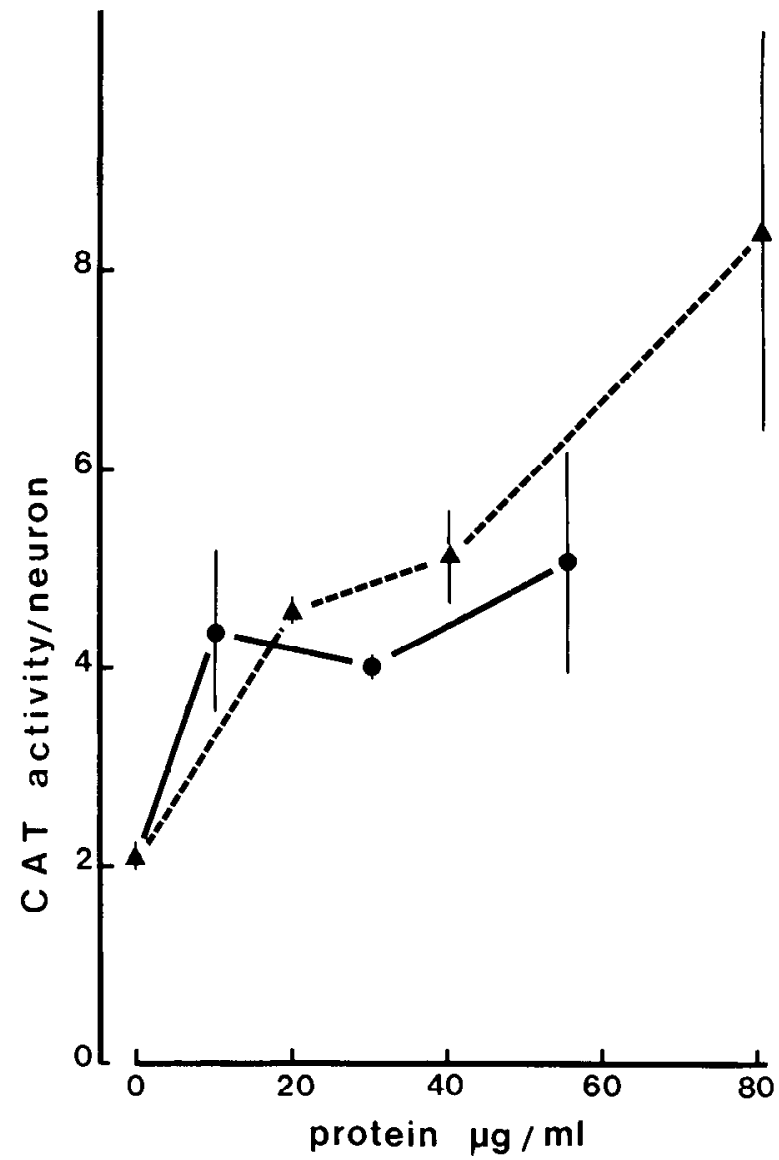

Figure 7. Dose-response curves of CAT stimulation by 2 fractions purified from $\mathrm{CM}$. Cultures of fraction $\mathrm{A}$ from a density gradient were cultured for $7 \mathrm{~d}$ in the presence of CM-cellulose fraction $1(--)$ or fraction HA (-). The data are means \pm SEM for 3 sister cultures. Neither fraction had any significant effect on neuronal survival.

Using Lucifer yellow-conjugated WGA and fluorescence analysis with a flow cytometer, Schaffner et al. (1987) reported the labeling of $14 \%$ of ventral spinal cord cells as compared to $3 \%$ reported by Smith et al. (1986) using WGA-LY and fluorescence microscopy. These 2 values are distinctly higher than that (about $1 \%$ of LMC cells) we found with diI and fluorescence micros-

Table 3. Regulation of CAT activity in cultures of motoneurons purified by the blind-sorting procedure

\begin{tabular}{|c|c|c|c|c|}
\hline & Neuron/dish number & $\begin{array}{l}\text { Percent- } \\
\text { age of } \\
\text { initial } \\
\text { value }\end{array}$ & CAT activity/dish & $\begin{array}{l}\mathrm{CAT} \\
\text { activity/neuron }\end{array}$ \\
\hline \multicolumn{5}{|l|}{ Experiment 1} \\
\hline Fresh medium & $7880 \pm 346(100)$ & $65 \%$ & $5128 \pm 200(100)$ & $0.65 \pm 0.07(100)$ \\
\hline $50 \% \mathrm{CM}$ & $11,166 \pm 334(142)$ & $93 \%$ & $15,708 \pm 600(306)^{a}$ & $1.40 \pm 0.09(215)$ \\
\hline \multicolumn{5}{|l|}{ Experiment 2} \\
\hline Fresh medium & $1506 \pm 29(100)$ & $26 \%$ & $2871 \pm 612(100)$ & $3.73 \pm 0.85(100)$ \\
\hline $\begin{array}{l}\text { CM-cellulose fraction } 1 \\
(25 \mu \mathrm{g} / \mathrm{ml})\end{array}$ & $1572 \pm 75$ & $28 \%$ & $4683 \pm 178(163)^{b}$ & $5.95 \pm 0.11(160)$ \\
\hline
\end{tabular}

Motoneurons from uninjected embryos were purified by cell sorting using only light-scatter criteria. Cells $\left(1.2 \times 10^{4}\right.$ for experiment $1,5.7 \times 10^{3}$ for experiment 2) were sorted in $16 \mathrm{~mm}$ wells containing monolayers of astrocytes and cultured from day 0 onwards in the conditions indicated. The data are means \pm SEM for 3 sister cultures. Values in parentheses are percentages of the data obtained with fresh medium.

${ }^{a}$ Differs from control at $p<0.001$.

${ }^{b}$ Differs from control at $p<0.01$. 
Figure 8. Triparametric analysis of cells labeled with diI. The events analyzed by the cell sorter were characterized by their fluorescence intensity and the light scattering produced at low angles (axial scatter) and right angle (orthogonal scatter). Each combination of these 3 parameters was used to generate a $3 \mathrm{D}$ histogram where the number of events is plotted on the vertical axis. Arrows point toward increasing values. Panel A was rotated so that the foot of peak III was evident; motoneurons are localized in this region (see Materials and Methods). In this experiment, cells dissociated from the lumbar motor columns were not centrifuged through a layer of BSA, resulting in a large peak (I) composed of cellular debris.
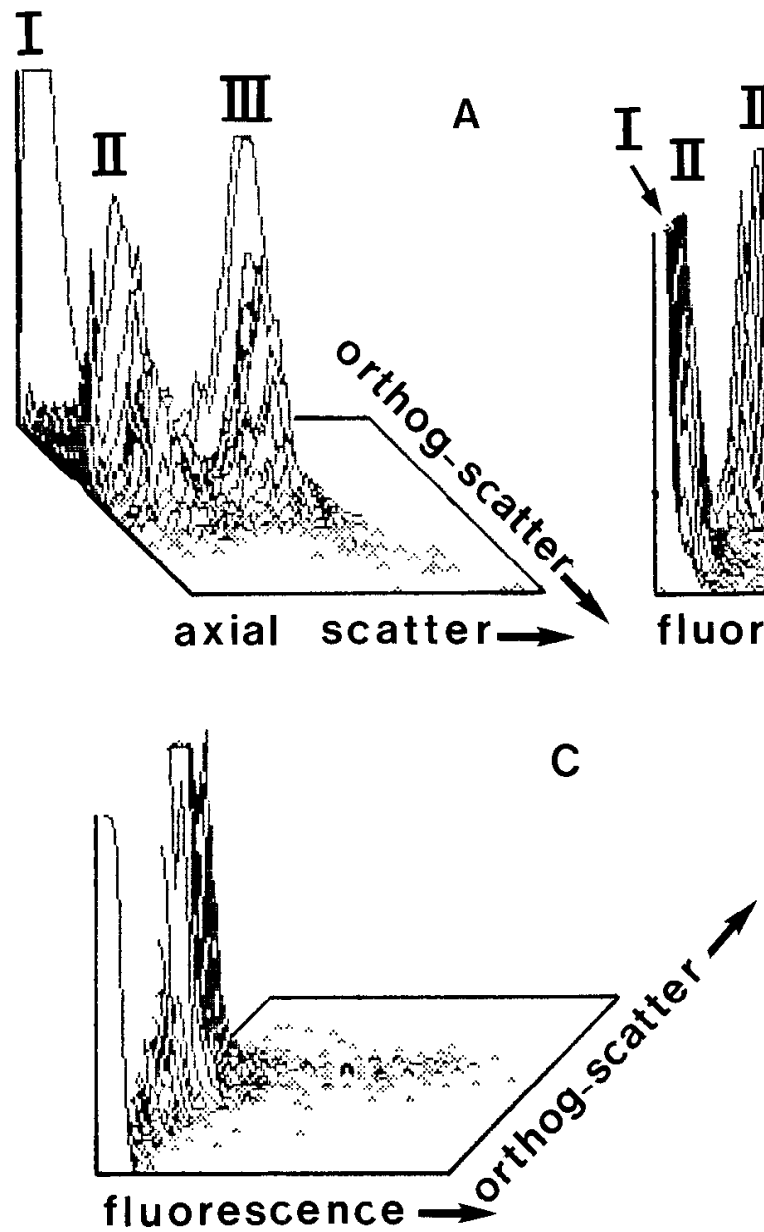

B

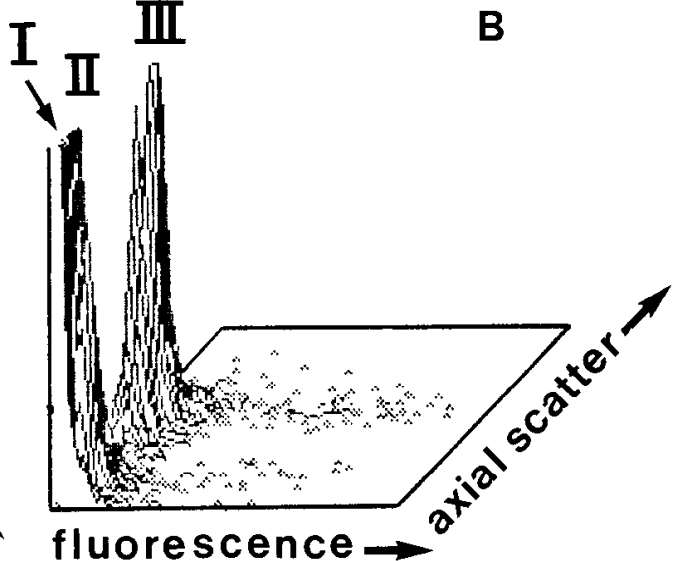

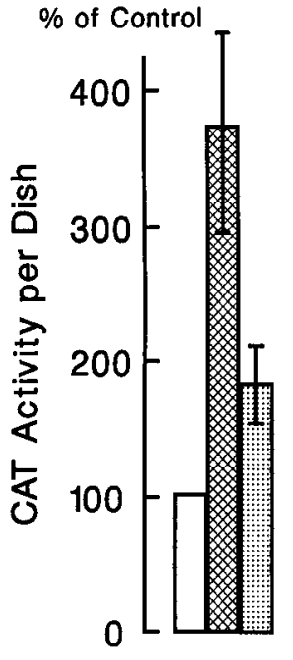
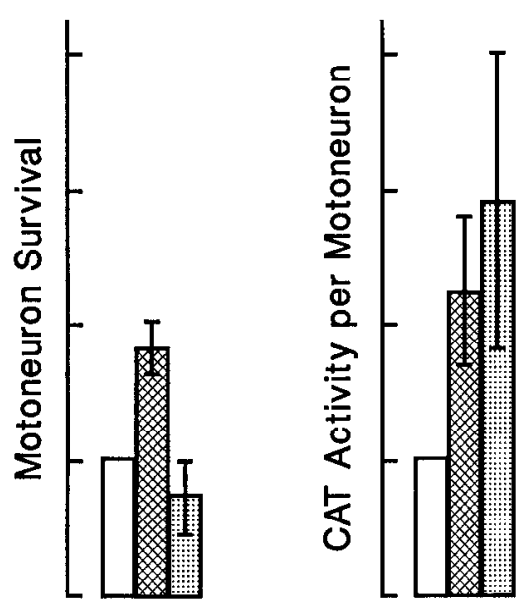

Figure 9. Effects of $\mathrm{CM}$ and $\mathrm{CM}$-cellulose fraction 1 on the survival and CAT activity of pure motoneurons. Motoneurons were purified by fluorescence-activated cell sorting and cultured for 8-10 d in control medium (clear bars) or the presence of $50 \% \mathrm{CM}$ (hatched bars) or of $25 \mu \mathrm{g} / \mathrm{ml}$ of CM-ccllulosc fraction 1 (spotted bars). The data are from $6(50 \% \mathrm{CM})$ or $3(\mathrm{CM}$-cellulose fraction 1) experiments, each comprising 2-3 cultures of each group. To correct for interexperiment variabilities in motoneuron numbers and CAT activities, the data are expressed as percentages of control values. copy. The causc of these differences is probably 2 -fold. First, FACS analysis may indicate higher percentages than visual observation, depending upon the threshold chosen for analysis. Second, it is possible that fluorescent lectins, which can to a certain extent diffuse in muscle extracellular spaces, label a higher proportion of motoneurons than liposoluble dyes like diI which incorporate in nerve terminals only near the injection point (see Catsicas et al., 1987).

\section{Purification of embryonic motoneurons}

Motoneurons from rat embryos have been enriched about 4-fold by centrifugation on metrizamide density gradients (Schnaar and Schaffner, 1981; Smith et al., 1986). In this study, motoneurons have been purified on a gradient made of Nycodenz, a nonionic, iodinated compound used to purify blood cells (Boyum, 1983). Starting with cclls dissociated from the entire spinal cord, 12-fold increases in the percentage of fluorescent cells and in CAT activity were obtained; the combination of the dissection of the LMC and the density-gradient centrifugation resulted in a 30 - to 40 -fold increase in the proportion of diI-labeled cells. The percentage obtained $(5-7 \%)$ allowed the purification of sizable quantities of motoneurons by cell sorting.

For cell sorting, we used as criteria the intensity of fluorescence and the light scattering at low angles and at $90^{\circ}$. The 
threshold of fluorescence intensity used (channel 66) was well above the level of autofiuorescence. We thus eliminated unlabeled cells that had adsorbed debris of fluorescent cells. Sorting cells just above the threshold of autofluorescence, Schaffner et al. (1987) reported that only $50 \%$ of sorted cells were scored as fluorescent in a second analysis. Using a high threshold, it is, however, possible that we eliminated weakly fluorescent cells and that we selected a population of more mature motoneurons.

The orthogonal light scatter was not used as a sorting criterion in previous studies of motoneuron purification (Eagelson and Bennett, 1983; Calof and Reichardt, 1984; O'Brien and Fischbach, 1986; Schaffner et al., 1987). In combination with the axial light scatter, it allowed us to define a population containing 95-98\% living cells. Moreover, the use of the 2 light-scatter parameters allowed us to purify to $>50 \%$ unlabeled motoneurons. Although resulting in impure motoneurons, this method is more rapid and gives higher motoneuron yields than conventional methods.

\section{Effects of CM on the survival of motoneurons}

Using low-density cultures of cells purified by centrifugation, we found that CM had a beneficial effect on the survival of diIlabeled motoneurons, whereas the survival of other spinal cord neurons was unaffected. In agreement with previous studies (Bennett et al., 1980; Slack and Pockett, 1982; Calof and Reichardt, 1984; Dohrmann et al., 1986, 1987; O'Brien and Fischbach, 1986), CM had also a beneficial effect on the survival of motoneurons purified by cell sorting, but it was distinctly smaller than that observed with partially purified motoneurons. It is thus conceivable that interneurons, in cooperation with $\mathrm{CM}$ factors, contribute to motoncuron survival. Alternatively, the criteria used for cell sorting may have selected a subpopulation of motoneurons less sensitive to muscle-CM survival factors. It is known that, during development, the survival of motoneurons becomes independent of a contact with muscle (Eagleson and Bennett, 1986).

The identity of motoneuron survival factors in CM remains unknown. In another study, we found that the entire population of motoneurons purified by cell sorting could be maintained in culture for a week in the presence of transforming growth factor $\beta_{1}$ (J. C. Martinou et al., unpublished observations). Other factors affecting motoneuron survival in culture include a low- $M$, peptide from muscle extracts (McManaman et al., 1985; Smith et al., 1986), neuroleukin (Gurney et al., 1986), basic fibroblast growth factor (Unsicker et al., 1987; Anderson et al., 1988), and chick ciliary neuronotrophic factor (Barbin et al., 1984).

\section{Characterization of 2 CAT-stimulating factors from $C M$}

In addition to its survival promoting effect, we found that $\mathrm{CM}$ stimulated about 2-fold CAT activity in motoneurons purified by cell sorting. On the contrary, the stimulation of CAT development caused by $\mathrm{CM}$ in heterogeneous cultures enriched in motoneurons was quantitatively attributed to its effects on motoneuron survival. This suggests that motoncurons purified by cell sorting are more sensitive to CAT-stimulating factors, although dose-response curves with pure factors remain to be established.

With the fractionation steps used by Weber (1981) and Fukada (1985) to purify a factor that induces cholinergic traits in sympathetic neurons, we have partially purified 2 factors from CM that increase CAT development in motoneurons without affecting their survival. In agreement with earlier data (Giess and Weber, 1984), one of these is basic and copurifies during a 4-step fractionation procedure with the cholinergic factor for sympathetic neurons. Further purification remains necessary to establish the similarity of these 2 factors. In contrast, a second, neutral CAT-stimulating factor for motoneurons is totally inactive on newborn rat sympathetic neurons. Its apparent $M_{r}$ has not yet been characterized, so that a comparison with the cholincrgic factors charactcrized by Smith ct al. (1985) cannot bc made. From its behavior on a DEAE-cellulose column, the new factor appears different from that purified by McManaman et al. (1988).

Although the CAT-inducing effect of CM on sympathetic neuron cultures has been attributed to a single factor (Weber, 1981; Fukada, 1985; Weber et al., 1985), the effect of muscle-CM on the development of CAT activity in motoneurons clearly involves multiple molecules. Those that enhance the survival of motoneurons remain to be characterized, whereas we have partially purified 2 molecules that stimulate the differentiation of motoneurons without affecting their survival. One of the factors may also induce CAT expression in sympathetic neurons (Giess and Weber, 1984), as well as in sensory neurons originating from the placodes (Mathieu et al., 1984). A second factor appears to be more specific for motoneurons. Both of them may be implicated in retrograde trophic interactions between muscles and motoneurons.

\section{References}

Anderson, K. J., D. Dam, S. Lee, and C. W. Cotman (1988) Basic fibroblast growth factor prevents death of lesioned cholinergic neurons in vivo. Nature 332: 360-361.

Barbin, G., M. Manthorpe, and S. Varon (1984) Purification of the chick eye ciliary neuronotrophic factor. J. Neurochem 43: 1468-1478.

Bennett, M. R., K. Lai, and V. Nurcombe (1980) Identification of embryonic motoneurons in vitro: Their survival is dependent on skeletal muscle. Brain Res. 190: 537-542.

Boyum, A. (1983) Isolation of human blood monocytes with Nycodenz, a new nonionic iodinated gradient medium. Scand. J. Immunol. 17: 429-436.

Calof, A. L., and L. F. Reichardt (1984) Motoneurons purified by cell sorting respond to two distinct activities in myotube-conditioned medium. Dev. Biol. 106: 194-210.

Calof, A. L., and L. F. Reichardt (1985) Response of purified chick motoneurons to myotube-conditioned medium: Laminin is essential for the substratum binding, neurite outgrowth promoting activity. Neurosci. Lett. 59: 183-189.

Catsicas, S., S. Thanos, and P. G. H. Clarke (1987) Major role for neuronal dcath during brain development: Refinement of topographical connections. Proc. Natl. Acad. Sci. USA 84: 8165-8168.

Chu-Wang, I. W., and R. W. Oppenheim (1978) Cell death of motoneurons in the chick embryo spinal cord. II. A quantitative and qualitative analysis of degeneration in the ventral cord, including evidence for axon outgrowth and limb innervation prior to cell death. J. Comp. Neurol. 177: 59-86.

Doherty, P., J. G. Dickson, R. P. Flanigan, and F. S. Walsh (1986) Human skeletal muscle cells synthesise a neuronotrophic factor reactive with spinal neurons. J. Neurochem. 46: 133-139.

Dohrmann, U., D. Edgar, M. Sendtner, and H. Thoenen (1986) Muscle-derived factors that support survival and promote fiber outgrowth from embryonic chick spinal motor neurons in culture. Dev. Biol. 118: 209-221.

Dohrmann, U., D. Edgar, and H. Thoenen (1987) Distinct neurotrophic factors from skeletal muscle and the central nervous system interact synergistically to support the survival of cultured embryonic spinal molor neurons. Dev. Biol. 124: 145-152.

Dribin, L. B., and J. N. Barrett (1980) Conditioned medium enhances neuritic outgrowth from rat spinal cord explants. Dev. Biol. 74: 184195.

Dribin, L. B., and J. N. Barrett (1982) Two components of conditioned 
medium increase neuritic outgrowth from rat spinal cord explants. J. Neurosci. Res. 8: 271-280.

Eagleson, K. L., and M. R. Bennett (1983) Survival of purified motor neurons in vitro: Effects of skeletal muscle-conditioned medium. Neurosci. Lett. 38: 187-192.

Eagleson, K. L., and M. R. Bennett (1986) Motoneuron survival requirements during development: The change from immature astrocytes dependence to myotube dependence. Dev. Brain Res. 29: 161172.

Fonnum, F. (1975) A rapid radiochemical method for the determination of choline acetyltransferase. J. Neurochem. 24: 407-409.

Fukada, K. (1985) Purification and partial characterization of a cholinergic neuronal differentiation factor. Proc. Natl. Acad. Sci. USA 82: 8795-8799.

Giess, M. C., and M. J. Weber (1984) Acetylcholine metabolism in rat spinal cord cultures: Regulation by a factor involved in the determination of the neurotransmitter phenotype of sympathetic neurons. J. Neurosci. 4: 1442-1452.

Giller, E. L. J. H. Neale, P. N. Bullock, B. K. Schrier, and P. G. Nelson (1977) Choline acetyltransferase activity of spinal cord cell cultures increased by coculture with muscle and by muscle-conditioned medium. J. Cell Biol. 74: 16-29.

Gurney, M. E., S. P. Heinrich, M. R. Lee, and H. S. Yin (1986) Molecular cloning and expression of neuroleukin, a neurotrophic factor for spinal and sensory neurons. Science 234: 566-574.

Hamburger, V. (1975) Cell death in the development of the lateral motor column of the chick embryo. J. Comp. Neurol. 160: 535-546.

Hamburger, V. (1977) The developmental history of the motor neuron. Neurosci. Res. Prog. Bul. (Suppl.) 15.

Henderson, C. E., M. Huchet, and J. P. Changeux (1981) Neurite outgrowth from embryonic chicken spinal neurons is promoted by media conditioned by muscle cells. Proc. Natl. Acad. Sci. USA 78: $2625-2629$

Henderson, C. E., M. Huchet, and J. P. Changeux (1983) Denervation increases a neurite promoting activity in extracts of skeletal muscle. Nature 302: 609-611.

Hildebrand, J. C., D. L. Barker, E. Herbert, and E. A. Kravitz (1971) Screening for neurotransmitters: A rapid radiochemical procedure. J. Neurobiol. 2: 231-246.

Hollyday, M., and V. Hamburger (1976) Reduction of the naturally occurring motor neuron loss by enlargement of the periphery. J. Comp. Neurol. $170: 311-320$

Honig, M. G., and R. I. Hume (1986) Fluorescent carbocyanine dyes allow living neurons of identified origin to be studied in long term cultures. J. Cell Biol. 103: 171-187.

Karnovski, M. J., and L. Roots (1964) A "direct coloring" thiocholine method for cholinesterases. J. Histochem. Cytochem. 12: 219-221.

Kaufman, L. M., S. R. Barry, and J. N. Barrett (1985) Characterization of tissue-derived macromolecules affecting transmitter synthesis in rat spinal cord neurons. J. Neurosci. 5: 160-166.

Lance-Jones, C. (1982) Motoneuron cell death in the developing lumbar spinal cord of the mouse. Dev. Brain Res. 4: 473-479.

Landmesser, L. (1978) The development of motor projection patterns in the chick hind limb. J. Physiol. (Lond.) 284: 391-414.

Levi-Montalcini, R. (1987) The nerve growth factor: Thirty five years later. EMBO J. 6: 1145-1154.

Martinou, J. C., F. Bierer, A. Le Van Thai, and M. Weber (1989) Influence of the culture substratum on the expression of choline acetyltransferase activity in purified motoneurons from rat embryos. Dev. Brain Res. 47: 251-262.

Mathieu, C., A. Moisand, and M. J. Weber (1984) Acetylcholine metabolism by cultured neurons from rat nodose ganglia: Regulation by a macromolecule from muscle-conditioned medium. Neuroscience 13: 1373-1386.

McCarthy, K. D., and J. DeVellis (1980) Preparation of separate astroglial and oligodendrogial cell cultures from rat central tissue. $\mathrm{J}$. Cell Biol. 85: 890-899.
McManaman, J., F. G. Crawford, S. S. Stewart, and S. H. Appel (1988) Purification of a skeletal muscle polypeptide which stimulates choline acetyltransferase activity in cultured spinal cord neurons. J. Biol. Chem. 263: 5890-5897.

McPheeters, M., and L. M. Okun (1980) Identification and isolation in vitro of presumptive motoneurons marked by retrograde transport of a new fluorescent tracer. Soc. Neurosci. Abstr. 6: 733.

O'Brien, R. J., and G. D. Fischbach (1986) Isolation of embryonic chick motoneurons and their survival in vitro. J. Neurosci. 6: 32653274.

Oppenheim, R. W., I. W. Chu Wang, and J. L. Maderdrut (1978) Cell death of motoneurones in the chick embryo spinal cord. III. The differentiation of motoneurones prior to their induced degeneration following limb-bud removal. J. Comp. Neurol. 177: 87-112.

Patterson, P. H., and L. L. Y. Chun (1977) The induction of acetylcholine synthesis in primary cultures of dissociated rat sympathetic neurons. I. Effects of conditioned medium. Dev. Biol. 56: 263-280.

Prestige, M. C. (1967) The control of cell number in the lumbar ventral horns during the development of Xenopus laevis tadpoles. J. Embryol. Exp. Morph. 18: 359-387.

Prestige, M. C. (1970) Differentiation, degeneration and the role of the periphery: Quantitative considerations. In Neurosciences: Second Study Program, pp. 73-82, Rockefeller University Press, New York.

Raynaud, B., N. Faucon-Biguet, S. Vidal, J. Mallet, and M. J. Weber (1987) The use of a tyrosine hydroxylase cDNA probe to study the neurotransmitter plasticity of rat sympathetic neurons in culture. Dev. Biol. 119: 305-312.

Saint-John, P. A., W. M. Kell, J. S. Mazzette, G. D. Lange, and J. L. Barker (1986) Analysis and isolation of embryonic mammalian neurons by fluorescence-activated cell sorting. J. Neurosci. 6: 1492-1512.

Schaffner, A. E., P. A. St. John, and J. L. Barker (1987) Fluorescenceactivated cell sorting of embryonic mouse and rat motoneurons and their long-term survival in vitro. J. Neurosci. 7: 3088-3104.

Schnaar, R. L., and A. E. Schaffner (1981) Separation of cell types from embryonic chicken and rat spinal cord: Characterization of motoneuron cnriched fractions. J. Neurosci. 1: 204-217.

Slack, J. R., and S. Pockett (1982) Motor neurotrophic factor in denervated adult skeletal muscle. Brain Res. 347: 138-140.

Smith, R. G., J. McManaman, and S. H. Appel (1985) Trophic effects of skeletal muscle extracts on ventral spinal cord neurons in vitro: Separation of a protein with morphologic activity from proteins with cholinergic activity. J. Cell Biol. 101: 1608-1621.

Smith, R. G., K. Vaca, J. McManaman, and S. H. Appel (1986) Selective effects of skeletal muscle extract fractions on motoneuron development in vitro. J. Neurosci. 6: 439-447.

Swerts, J. P., A. Le Van Thai, A. Vigny, and M. J. Weber (1983) Regulation of enzymes responsible for neurotransmitter synthesis and degradation in cultured rat sympathetic neurons. I. Effects of muscle conditioned medium. Dev. Biol. 100: 1-11.

Unsicker, K., H. Rcichert-Preibsch, R. Schmidt, B. Pettmann, G. Labourdette, and M. Sensenbrenner (1987) Astroglial and fibroblast growth factors have neurotrophic functions for cultured peripheral and central nervous system neurons. Proc. Natl. Acad. Sci. USA 84: 5459-5463.

Weber, M. (1981) A diffusible factor responsible for the determination of cholinergic functions in cultured sympathetic neurons. Partial purification and characterization. J. Biol. Chem. 246: 3447-3453.

Weber, M. J., and A. Le Van Thai (1982) Progress in the purification of a factor involved in the neurotransmitter choice made by cultured sympathetic neurons. In Embryonic Development, Part B: Cellular Aspects, M. M. Burger and R. Weber, eds., pp. 473-483, Alan R. Liss, New York.

Weber, M. J., B. Raynaud, and C. Delteil (1985) Molecular properties of a cholinergic differentiation factor from muscle-conditioned medium. J. Neurochem. 45: 1541-1547. 